LAW RENCE LIVERMORE N A T IO N A L LABORATORY

\section{A new damage testing system for detailed evaluation of damage behavior of bulk KDP and DKDP}

P. DeMange, R. A. Negres, C. W. Carr, H. B. Radousky, S. G. Demos

December 1, 2004

Boulder Damage Symposium

Boulder, CO, United States

September 20, 2004 through September 22, 2004 
This document was prepared as an account of work sponsored by an agency of the United States Government. Neither the United States Government nor the University of California nor any of their employees, makes any warranty, express or implied, or assumes any legal liability or responsibility for the accuracy, completeness, or usefulness of any information, apparatus, product, or process disclosed, or represents that its use would not infringe privately owned rights. Reference herein to any specific commercial product, process, or service by trade name, trademark, manufacturer, or otherwise, does not necessarily constitute or imply its endorsement, recommendation, or favoring by the United States Government or the University of California. The views and opinions of authors expressed herein do not necessarily state or reflect those of the United States Government or the University of California, and shall not be used for advertising or product endorsement purposes. 


\title{
A new damage testing system for detailed evaluation of damage behavior of bulk KDP and DKDP
}

\author{
P. DeMange, R. A. Negres, C. W. Carr, H. B. Radousky, and S. G. Demos \\ Lawrence Livermore National Laboratory, 7000 East Avenue, Livermore, California 94551
}

\begin{abstract}
We describe a new damage testing approach and instrumentation that provides quantitative measurements of bulk damage performance versus fluence for several frequencies. A major advantage of this method is that it can simultaneously provide direct information on pinpoint density and size, and beam obscuration. This allows for more accurate evaluation of material performance under operational conditions. Protocols for laser conditioning to improve damage performance can also be easily and rapidly evaluated. This damage testing approach has enabled us to perform complex experiments toward probing the fundamental mechanisms of damage initiation and conditioning.
\end{abstract}

\section{INTRODUCTION}

Laser-induced damage in KDP and DKDP is an important issue in the development of large-aperture laser systems. ${ }^{1}$ Socalled "pinpoint" damage sites arise in these materials at laser intensities at least an order of magnitude below their expected intrinsic breakdown intensities. A large density of damage pinpoints and/or large-size pinpoints result in beam obscuration and downstream intensity modulations. Recent results suggest the presence of clusters of intrinsic defects and/or foreign impurities responsible for localized absorption leading to the formation of damage sites. ${ }^{2-9}$

Current damage-testing methods rely on measuring the damage probability as a function of fluence. ${ }^{9-14}$ This method is most suitable for small optics; however, for ICF class components - where a small amount of damage does not hinder overall performance - measuring the density and size of damage pinpoints and the resulting beam obscuration is desirable. In this work, we introduce a new experimental system for off-line assessment of damage performance that simultaneously provides direct information on pinpoint density and size and resulting beam obscuration. We demonstrate the feasibility of this approach to reveal basic properties of the material associated with its susceptibility to laser-induced damage. Specifically, we show preliminary results on the behavior of laser damage performance and laser conditioning under a wide range of laser parameters.

\section{EXPERIMENTAL SETUP}

A schematic of the damage testing instrumentation depicting the primary components is shown in Fig. 1. The main laser source is a pulsed Nd:YAG laser. The fundamental (at $1064 \mathrm{~nm}$ ), second, and third harmonics of the output are separated using high reflectivity mirrors selective to each frequency. The average fluence of each beam is adjusted using a computer controlled waveplate (WP) and a polarizer (POL). The three beams are then aligned to co-propagate on the main beam path and focused by a $200-\mathrm{mm}$ focal length cylindrical lens to the bulk of the material. The beams focus to a $1 / \mathrm{e}^{2}$ height of $3000 \mu \mathrm{m}$ and widths of $90 \mu \mathrm{m}, 60 \mu \mathrm{m}$, and $40 \mu \mathrm{m}$ for $1 \omega, 2 \omega$ and $3 \omega$, respectively. In order to focus each frequency to the same location in the bulk of the crystal, we have positioned galilean telescopes (TS) in each beam line to adjust their divergence before recombination. The beam spatial profiles are measured using a 0.25 by $0.25 \mathrm{inch}^{2} \mathrm{CCD}$ camera with a pixel resolution of $\sim 5 \mu \mathrm{m}$. 


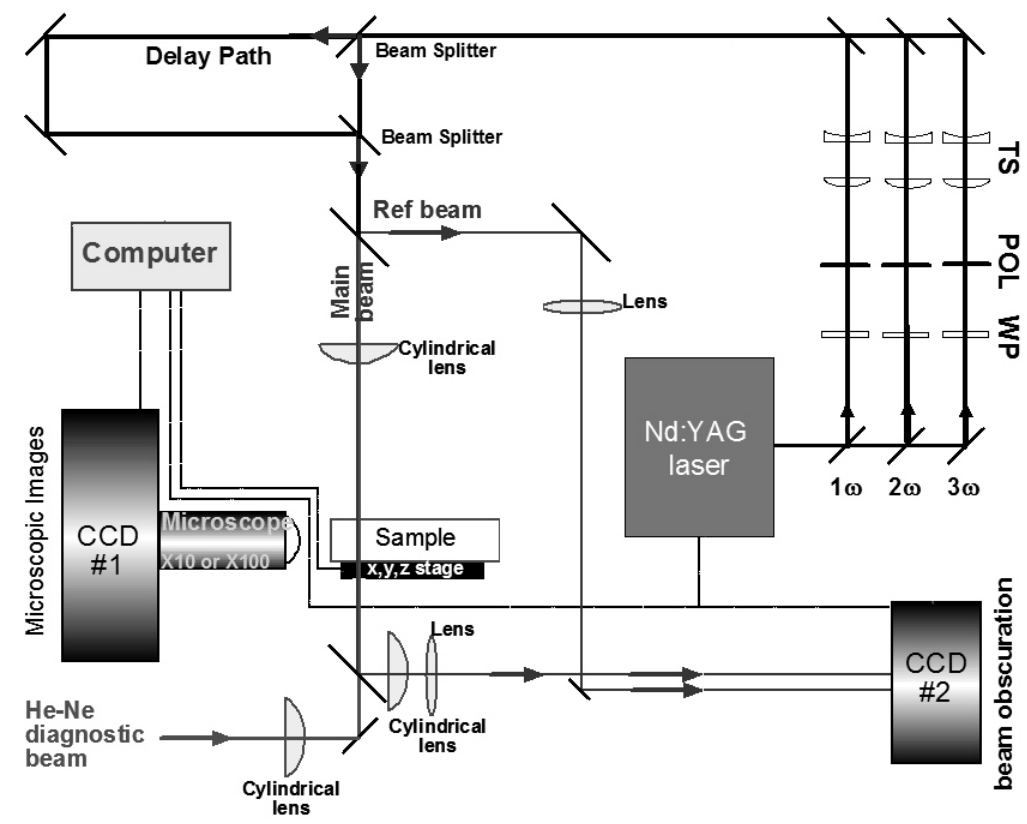

Figure 1. Experimental setup of damage performance testing system. A detailed description is provided in the text.

The samples were cut to $1 \times 5 \times 5 \mathrm{~cm}^{3}$ in size plates and polished on all sides. Bulk damage is produced through the focal range of the cylindrical lens, $\sim 8000 \mu \mathrm{m}$. A counter-propagating 632.8-nm beam from a HeNe laser is focused by a cylindrical lens $(\mathrm{f}=250 \mathrm{~mm}$ ) through the back of the sample to illuminate any resulting damage pinpoints within the tested volume. Images of the damaged region are captured orthogonally to the direction of propagation of the lasers, through the side of the sample using a microscope system. Assessment of the damage density is performed using $\% 2$ magnification microscope objective followed by $\% 5$ magnification lens which project an image of the damaged volume onto the chip of CCD \#1. This provides a $4.7 \mu \mathrm{m}$ by $4.7 \mu \mathrm{m}$ per pixel resolution. The images capture $5.9 \mathrm{~mm}$ in length of the damaged volume along the direction of propagation of the beam.

To measure the damage pinpoint density and correlate to the laser fluence, images are separated vertically into zones. The number of pinpoints in each zone is counted and a gaussian fit of the average pinpoint density of each zone is correlated to the gaussian fluence profile of the damaging pulsed beam. The pinpoint density as a function of fluence is then extracted. This approach allows for simultaneous measurement of pinpoint density for a range of laser fluences.

To measure the damage pinpoint sizes, the cw HeNe beam used to illuminate the damaged volume is replaced with a white light source. This is done to eliminate interference effects associated with monochromatic scattering. The $\% 2$ magnification microscope objective is replaced with a $\% 20$ magnification microscope objective to provide $0.47 \mu \mathrm{m}$ by $0.47 \mu \mathrm{m}$ per pixel resolution.

The beam obscuration is measured by capturing an image of the propagating beam through the damage volume and compared to a reference beam. A wedged window situated before the cylindrical lens sends a reference beam along one path. The beam transmitted through the damaged volume is sent along another path. Both beams are focused directly on CCD \#2 and an image is captured. The integrated pixel intensities of each beam are then calculated. The percent beam obscuration is calculated by comparing these intensities to those calculated from an image captured before damaging the bulk. Several images can be averaged before and after damaging the bulk for better statistics. The percent beam obscuration can then be correlated to pinpoint density, and ultimately a prediction of the percent beam obscuration for operation at a given fluence can be obtained. 
To approximate variable pulse-length, a 50/50 beamsplitter is placed in the path of the beam to send half of each pulse along an adjustable delay path before recombining with the leading half of the pulse, as shown in Fig. 1. This can be done independently for each laser frequency. In addition, experiments using two or more frequencies can be performed. Such experiments can explore damage behavior under simultaneous irradiation at two different frequencies or at different frequencies and delay times.

\section{EXPERIMENTAL RESULTS}

To demonstrate the capabilities of our experimental approach, we will present a number of preliminary results depicting the various aspects of laser-induced damage characteristics in KDP and DKDP crystals. The samples used in this work were obtained from crystals that were grown both conventionally and using the fast growth method.

\subsection{Measuring Pinpoint Density vs. Fluence}

Pristine bulk sites in a rapid-growth DKDP crystal were exposed to one pulse at the second harmonic of the Nd:YAG laser. The pinpoint density versus fluence profile was extracted from images obtained from five sites, each exposed to a single damaging pulse, following the analysis described in the previous section. Figure 2a shows a fit of the pinpoint density versus fluence profile. The same plot on semi-log scale in Fig. $2 b$ clearly illustrates the damage threshold fluence of the material as estimated from the fit to the data.
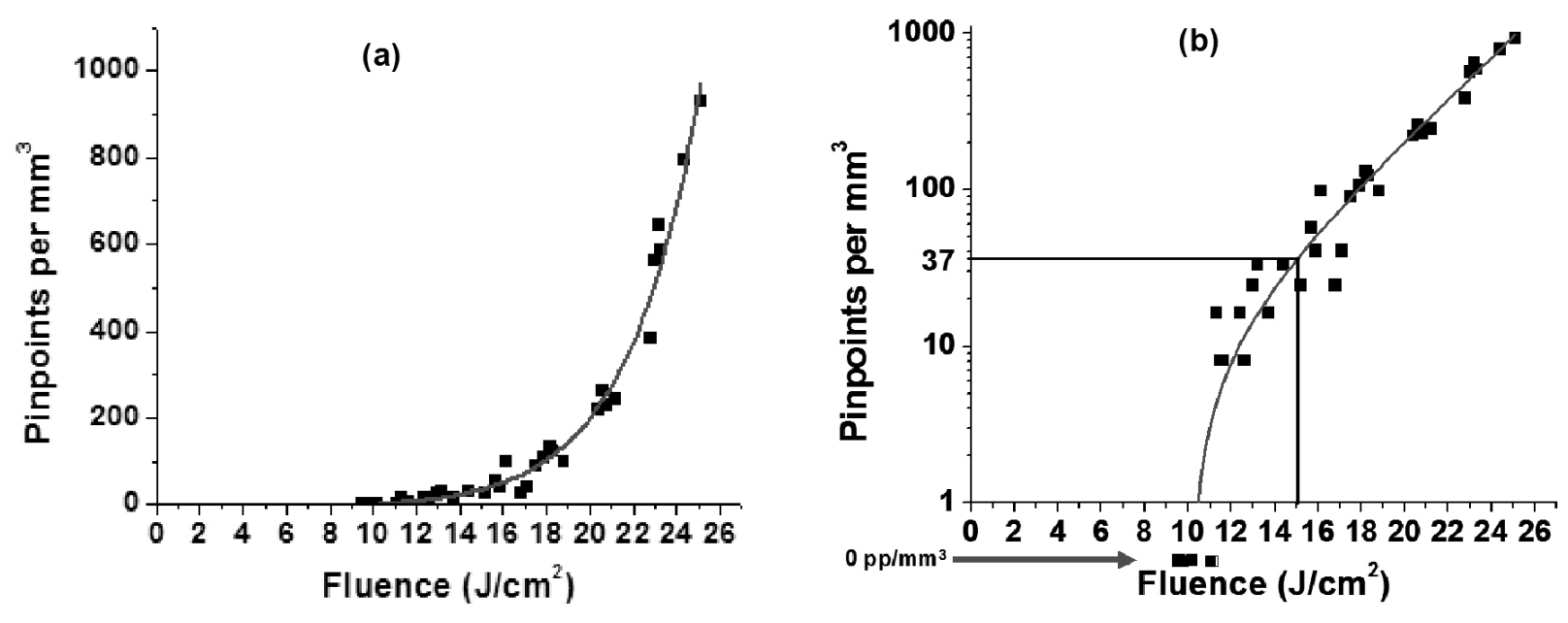

Figure 2. a) A polynomial fit of the damage density curve extrapolates to a damage threshold fluence of $10.4 \mathrm{~J} / \mathrm{cm}^{2}$. b) Damage density curve on $\log$ scale shows a fluence of $15.0 \mathrm{~J} / \mathrm{cm}^{2}$ corresponding to an obscuration limit of $0.1 \%\left(37\right.$ pinpoints per $\mathrm{mm} \mathrm{m}^{3}, 4 \mu \mathrm{m}$ in diameter), a significant increase in fluence from the damage threshold fluence of $10.4 \mathrm{~J} / \mathrm{cm}^{2}$.

\subsection{Measuring Beam Obscuration}

The beam obscuration was measured by recording ten images of the incident and transmitted beams at sub-damage laser fluence before and after exposure of the sample to a single high power laser pulse giving rise to formation of damage pinpoints (see Fig. 3). The damaged volume extended over a range of $5800 \mu \mathrm{m}$ and contained an average damage pinpoint density of $\sim 5300$ pinpoints per $\mathrm{mm}^{3}$. Using the $\times 20$ microscope objective, white light scattering images revealed the diameter of the damage pinpoints to be $4 \pm 1 \mu \mathrm{m}$. The resulting percent loss of the pulsed beam (excluding scattering at small angles) was $8.45 \pm 0.73 \%$. This implies that a beam loss of $\sim 14.3 \%$ is expected for beam propagation through $1 \mathrm{~cm}$ at the same pinpoint density. Assuming a linear dependence of beam obscuration on the 
pinpoint density, a beam loss limit of $0.1 \%$ would correlate to a pinpoint density of $\sim 37$ pinpoints per $\mathrm{mm}^{3}$. From the damage density curve shown in Fig. 2b, a density of 37 pinpoints per $\mathrm{mm}^{3}$ is created by a damaging fluence of 15.0 $\mathrm{J} / \mathrm{cm}^{2}$. This means that operating below $15.0 \mathrm{~J} / \mathrm{cm}^{2}$ will result in safe levels of beam loss for this particular material, assuming damage pinpoints of $4 \mu \mathrm{m}$ in diameter.

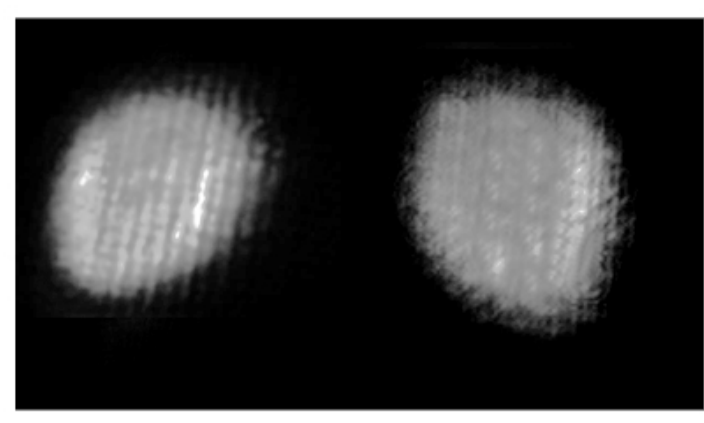

Figure 3. a) Image of the reference beam (right) and obscured beam (left) prior to damaging.

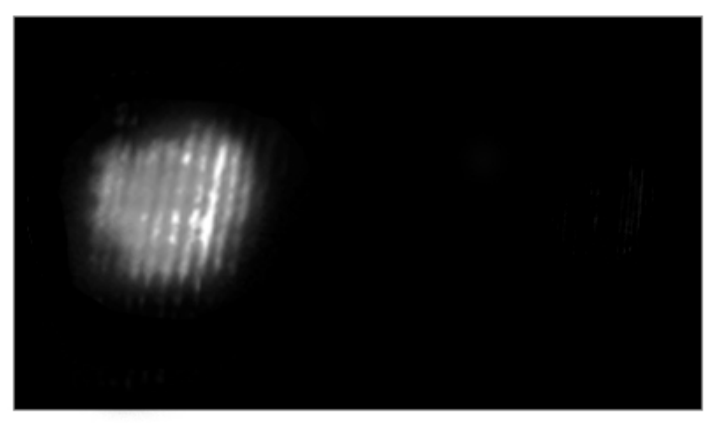

b) The subtraction of an image captured after damaging from an image captured before damaging shows the obscuration of the beam from the presence of damage.

\subsection{The Effect of Pulse-Length on Damage Pinpoint Sizes}

The sizes of damage pinpoints have a big impact on the level of laser beam obscuration. A two pulse experiment using a $6 \mathrm{~ns}$ delay between two, same intensity $3 \omega, 3$-ns pulses of $10 \mathrm{~J} / \mathrm{cm}^{2}$ in fluence was performed in KDP to study the dependence of damage pinpoint size on pulse-length. An image of damage sites formed by the damaging double-pulse is

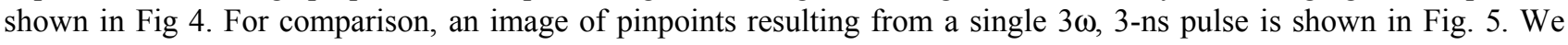
postulate that the second pulse is depositing a large amount of energy on the plasma created at damage sites from the first pulse giving rise to more severe damage as observed in Fig. 4.

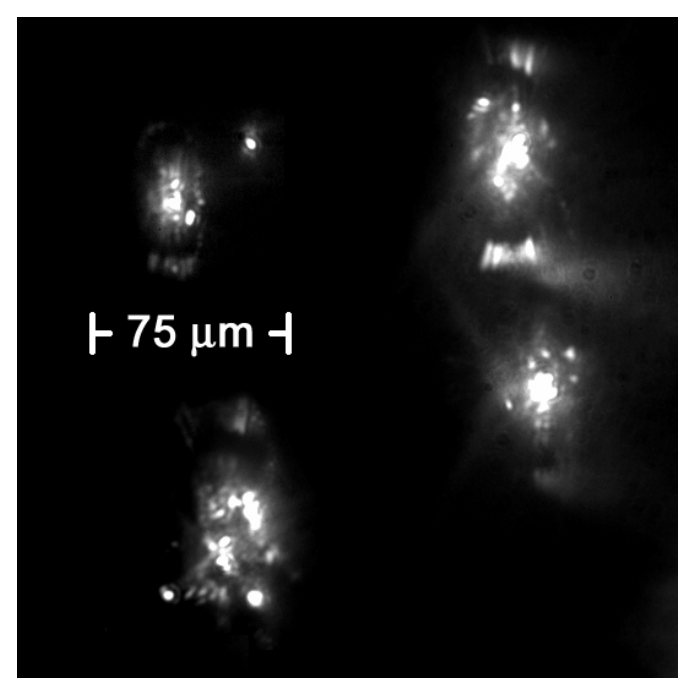

Figure 4. Damage spot created by two $10 \mathrm{~J} / \mathrm{cm}^{2}, 3-\mathrm{ns}$ pulses at $3 \omega$ with the second pulse delayed by $6 \mathrm{~ns}$. Longer pulses result in larger damage spots characteristically longer in one direction.

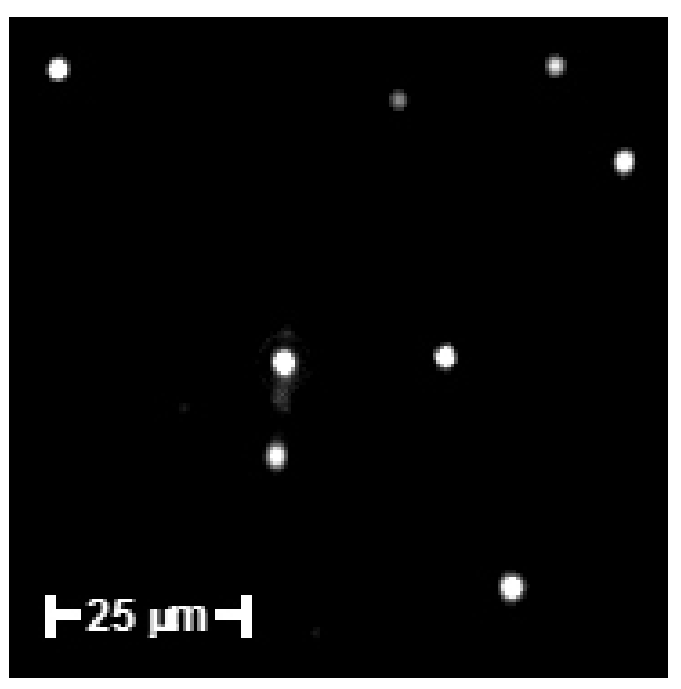

Figure 5. High-resolution white light scattering image of damage pinpoints resulting from a $3-n s, 3 \omega$ pulse. The diameters of the pinpoints are $4 \pm 1 \mu \mathrm{m}$. 


\subsection{Evaluation of Crystal Inhomogeneity}

Crystal inhomogeneity resulting in different damage thresholds and pinpoint densities for the same exposure has been observed in DKDP. Figure 6 shows an example in which damage testing a site with a single pulse resulted in two very different damage pinpoint densities within the same imaged area. More specifically, the pinpoint density on the lower left hand side was about ten times higher than the pinpoint density observed on the upper right hand side of this image. In general, this image depicts the two different damage behaviors we have seen in samples from the same boule.

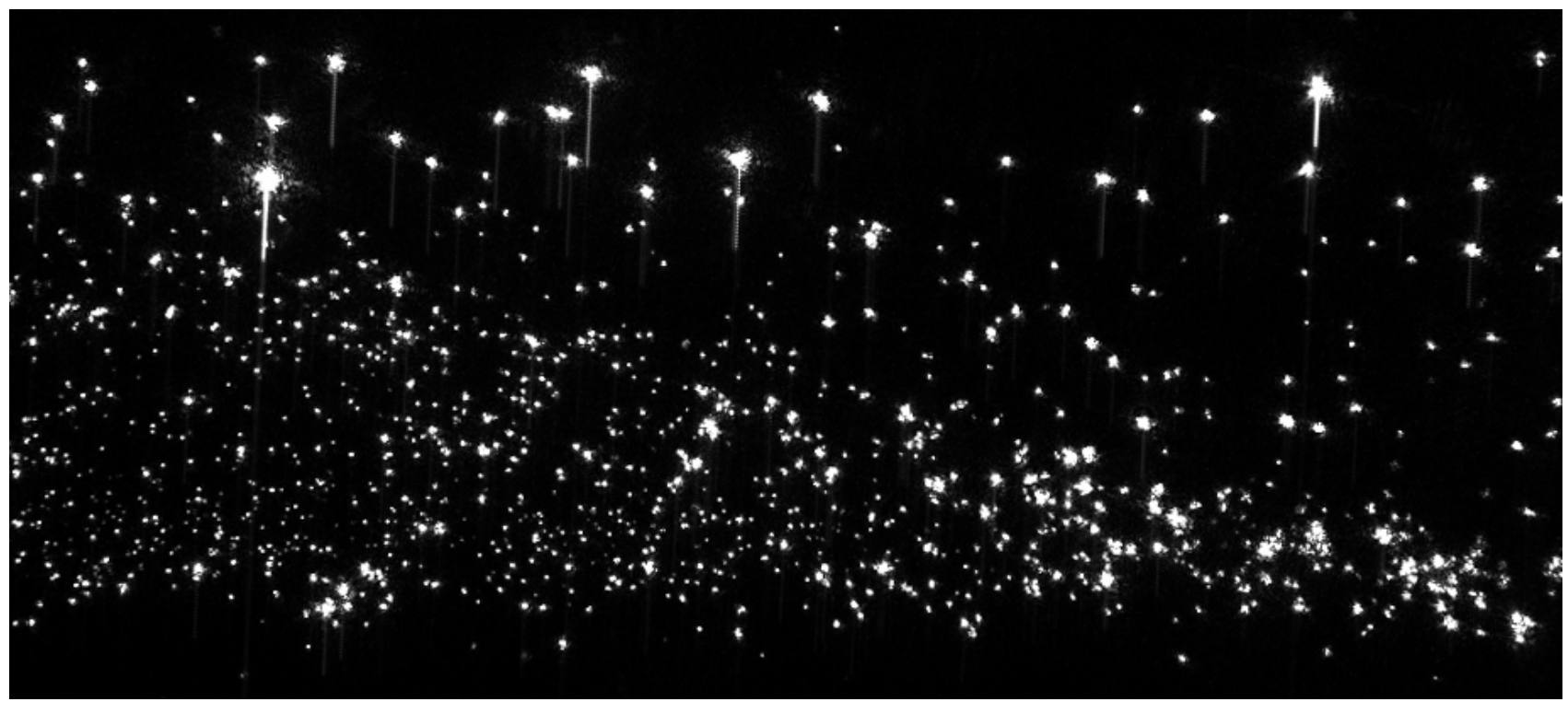

Figure 6. An image of damage pinpoints resulting from a single damage testing pulse in pristine material demonstrating material inhomogeneity.

\subsection{Laser Conditioning Effectiveness as a Function of Laser Pre-Exposure Parameters}

The ability of this system to provide a rapid quantitative evaluation of damage performance can also be utilized to investigate the behavior and fundamental mechanisms of laser damage and conditioning. As an example, Fig. 7 demonstrates that laser conditioning is observed as a change in pinpoint density for the same damage testing fluence. Figure 7a shows an image after exposure to a single damage testing pulse at $13 \mathrm{~J} / \mathrm{cm}^{2}$, resulting in $\sim 1950$ pinpoints per $\mathrm{mm}^{3}$ at peak laser fluence. Figure $7 \mathrm{~b}$ shows an image of a different site after exposure to eight pulses at $7 \mathrm{~J} / \mathrm{cm}^{2}$ for conditioning resulting in $\sim 110$ damage pinpoints per $\mathrm{mm}^{3}$ at peak fluence. Figure $7 \mathrm{c}$ shows an image of the same site (pre-exposed to eight pulses at $7 \mathrm{~J} / \mathrm{cm}^{2}$ ) following exposure to a single damage testing pulse at $13 \mathrm{~J} / \mathrm{cm}^{2}$. Both preexposure and damage testing result in a total pinpoint density of $\sim 230$ pinpoints per $\mathrm{mm}^{3}$ at peak laser fluence, significantly less than the $\sim 1950$ pinpoints per $\mathrm{mm}^{3}$ from damage testing at $13 \mathrm{~J} / \mathrm{cm}^{2}$ without pre-exposure.

Preliminary studies on the effectiveness of conditioning as a function of laser pre-exposure parameters were performed using three methods. More specifically, we measured the resulting damage density following pre-exposure a) using ramped fluence, $b$ ) with various fluences for same number of pulses, and c) with various numbers of pre-exposure pulses for same fluence. These measurements were performed for damage testing and pre-exposure at $2 \omega$ and $3 \omega$. These methods and experimental results are discussed in more detail below. 

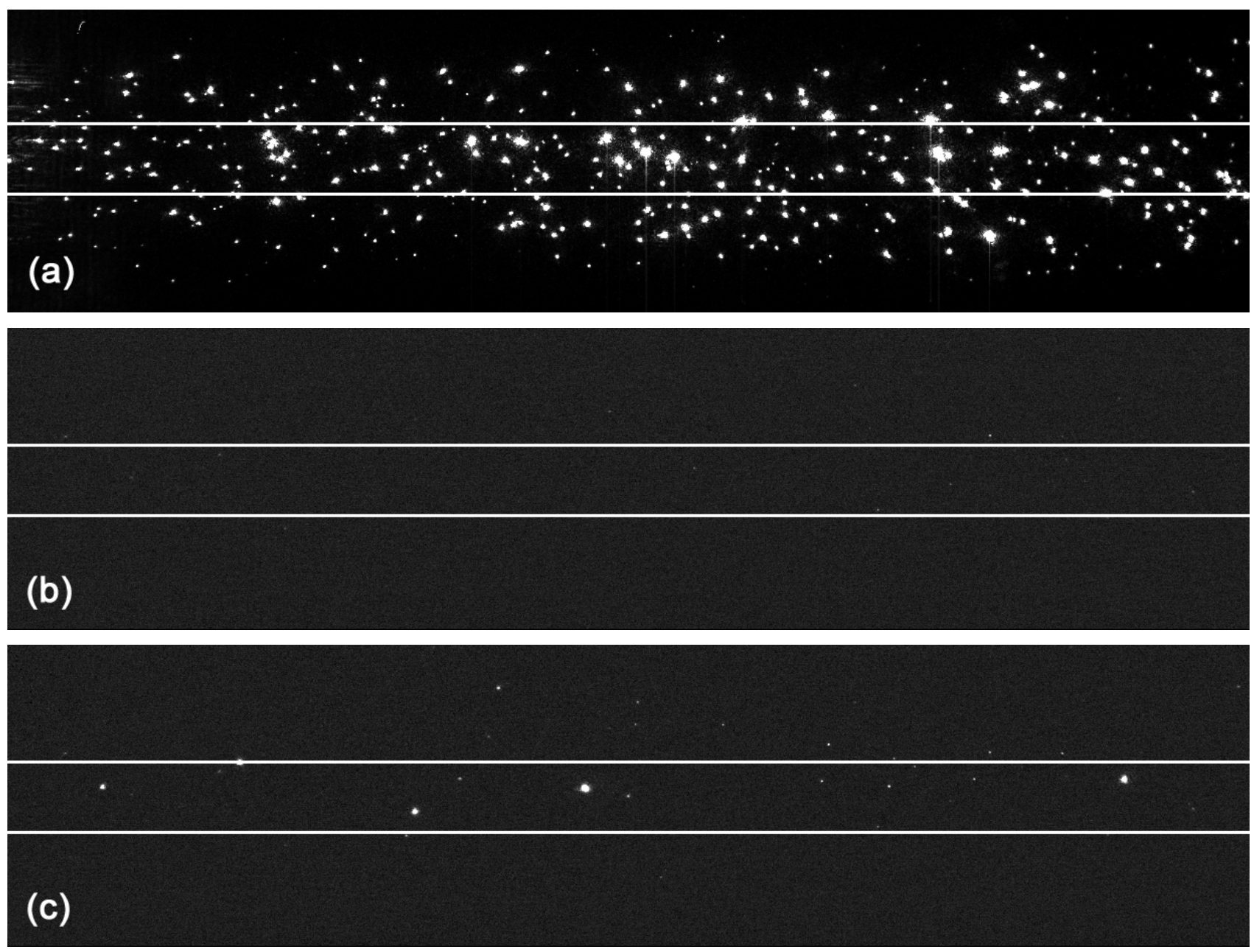

Figure. 7. Scatter images of pinpoint damage sites resulting from exposure to a) one pulse at $13 \mathrm{~J} / \mathrm{cm}^{2}$, b) ten pre-exposure pulses at 7 $\mathrm{J} / \mathrm{cm}^{2}$ at a new site, and c) one pulse at $13 \mathrm{~J} / \mathrm{cm}^{2}$ after pre-exposure to ten pulses at $7 \mathrm{~J} / \mathrm{cm}^{2}$. The image sizes are $1.4 \mathrm{~mm} \times 5.9 \mathrm{~mm}$.

\subsubsection{Ramped-pre-exposure method}

Ramped-fluence pre-exposure was used as a method to reveal optimal improvement to the damage performance at the four combinations of damage testing and pre-exposure at $2 \omega$ and $3 \omega$. A pristine (previously unexposed) volume of bulk material was irradiated with ramping fluence in $1 \mathrm{~J} / \mathrm{cm}^{2}$ increments, with ten pulses at each fluence increment. The fluence started at $1 \mathrm{~J} / \mathrm{cm}^{2}$ and was ramped up to the highest fluence at which no damage would be observed using the CCD camera, approximately $9 \mathrm{~J} / \mathrm{cm}^{2}$ at $3 \omega$ and $17 \mathrm{~J} / \mathrm{cm}^{2}$ at $2 \omega$. Due to fluctuations of the energy within each pulse, the highest average fluence reached during ramping was generally around $2 \mathrm{~J} / \mathrm{cm}^{2}$ below the damage threshold fluence at each frequency. Sites within the ramp-pre-exposed volume were then exposed to single damage testing pulses at various fluences and images of the resulting damage were captured for analysis. The damage pinpoint density was measured over a region of $338 \mu \mathrm{m}$ in width, representing the region of the crystal exposed only to peak laser fluence to within $5 \%$, which corresponds to a volume of $\sim 0.1 \mathrm{~mm}^{3}$. The pinpoint density was then plotted versus the peak damaging fluence.

Figure 8 shows the profiles of damage pinpoint density as a function of fluence for damage testing at $2 \omega$ and $3 \omega$. These profiles demonstrate the damage performance of a DKDP sample without pre-exposure and with pre-exposure using the ramped pre-exposure method. The plots are on a semi-log scale to better show the fluence of damage onset for each experiment. The pinpoint density profiles obtained under $2 \omega$ damage testing are shown in Fig. 8a. The damage threshold of the unconditioned material is found to be $\sim 12 \mathrm{~J} / \mathrm{cm}^{2}$. The results indicate that pre-exposure at $3 \omega$ increased 
the damage threshold to approximately $\sim 16 \mathrm{~J} / \mathrm{cm}^{2}$ while pre-exposure at $2 \omega$ increased the damage threshold to $\sim 19$ $\mathrm{J} / \mathrm{cm}^{2}$. The pinpoint density profiles obtained under 355-nm damage testing are shown in Fig. 8b. These results show that pre-exposure at $3 \omega$ increased the damage threshold to above $\sim 12 \mathrm{~J} / \mathrm{cm}^{2}$ from $\sim 6 \mathrm{~J} / \mathrm{cm}^{2}$ in the pristine material. Preexposure at $2 \omega$ results in a much smaller increase in the $3 \omega$ damage threshold to $\sim 8 \mathrm{~J} / \mathrm{cm}^{2}$. However, in both cases, the damage performance of the pre-exposed material begins to converge with that of the pristine material upon further increase in fluence.

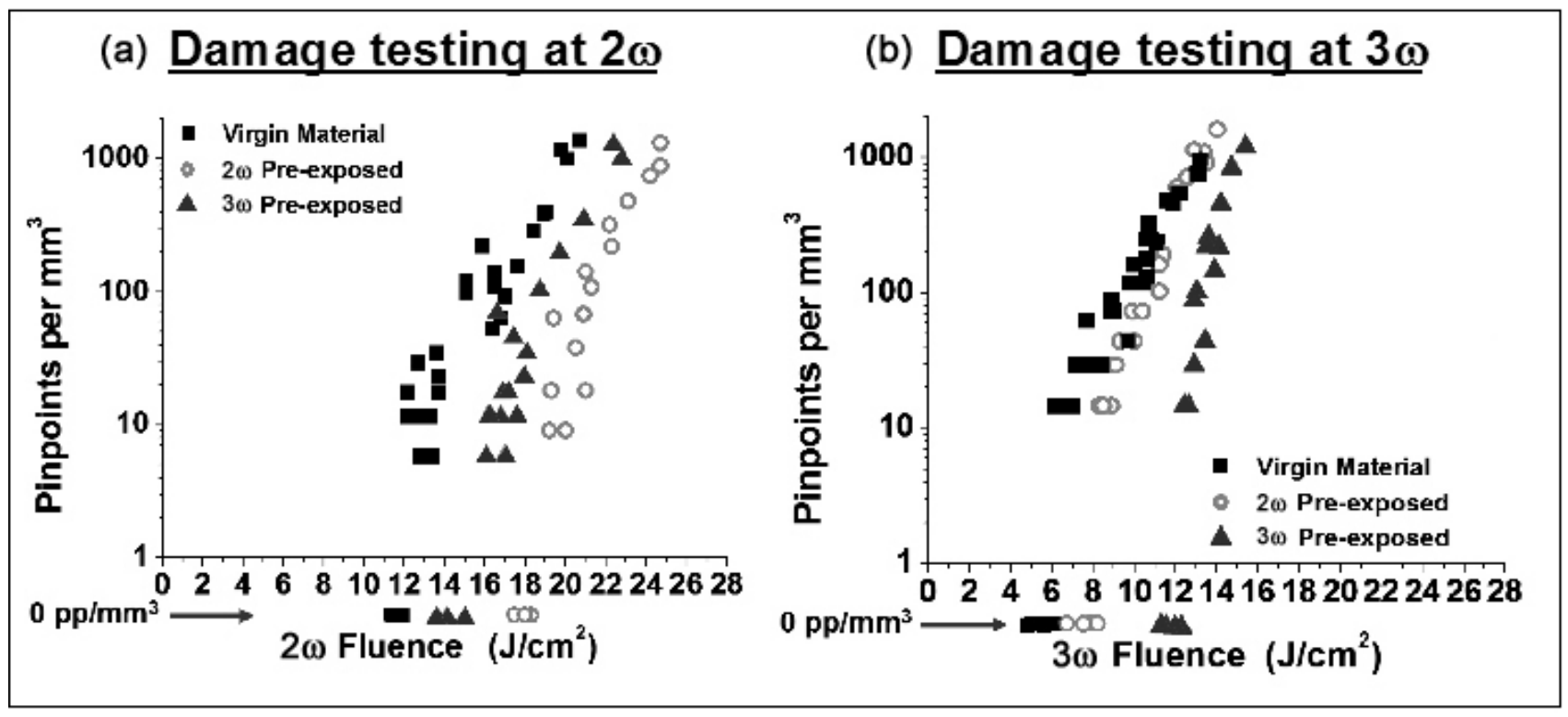

Figure 8. a) $2 \omega$ and b) $3 \omega$ damage density profiles for a KDP crystal sample on semi-log scale. $\mathbf{\square}=$ unconditioned, $\mathbf{0}=$ pre-exposed to $2 \omega, \boldsymbol{\Delta}=$ pre-exposed to $3 \omega$. The fluences for which no damage was observed are indicated by the arrow.

The results using the ramped pre-exposure method show the optimal level of improvement to the damage performance that may be achieved in KDP and DKDP crystals using the same laser pulse-length for damage and preexposure. ${ }^{15}$ Damage testing at $3 \omega$ indicated that pre-exposure at $2 \omega$ provides very little improvement while, in contrast, pre-exposure at $3 \omega$ shows significant improvement. Damage testing at $2 \omega$ demonstrated a significant improvement under pre-exposure to both, $2 \omega$ and $3 \omega$ pulses. However, pre-exposure to $2 \omega$ pulses provides best conditioning for $2 \omega$ operation as shown in Fig. 8a.

\subsubsection{Variable fluence pre-exposure method}

The dependence of conditioning on pre-exposure fluence was measured at combinations of damage testing and preexposure at $2 \omega$ and $3 \omega$. Pristine bulk sites were exposed first to ten pulses at constant fluence and then to a single higher fluence damaging pulse. The fluence of the damaging pulse remained the same while the fluence of the ten pre-exposure pulses was varied from site to site. Images were recorded prior to and after irradiation at a high fluence. The analysis of the resulting damage pinpoint density used the same technique described above for ramp-pre-exposure method. Following the damage testing pulse, only the pinpoint density at peak fluence is plotted versus the peak pre-exposure fluence.

Figure 9 shows profiles of the damage pinpoint density resulting from a single damage testing pulse at $20 \mathrm{~J} / \mathrm{cm}^{2}$ at $2 \omega$ (in Fig. 9a) and $16 \mathrm{~J} / \mathrm{cm}^{2}$ at $3 \omega$ (in Fig. 9b) following pre-exposure to ten pulses at the fluence displayed on the horizontal axis. The open and solid circle data points indicate pre-exposure to $3 \omega$ and $2 \omega$, respectively. Figure 9a demonstrates a linear decrease in the pinpoint density resulting from exposure to $20 \mathrm{~J} / \mathrm{cm}^{2}$ at $2 \omega$ with increase in the preexposure fluence. This is the case for pre-exposure at both $2 \omega$ and $3 \omega$ with the latter providing a greater level of 
conditioning at lower fluences. Figure $9 \mathrm{~b}$ indicates that pre-exposure at any fluence within the tested range of fluences at $2 \omega$ did not improve the damage performance for testing at $3 \omega$. Conversely, pre-exposure at $3 \omega$ shows a threshold fluence for conditioning. The pre-exposure fluence wherein the threshold for conditioning occurs is just below the damage threshold fluence of the unconditioned material $\left(\sim 7 \mathrm{~J} / \mathrm{cm}^{2}\right)$.

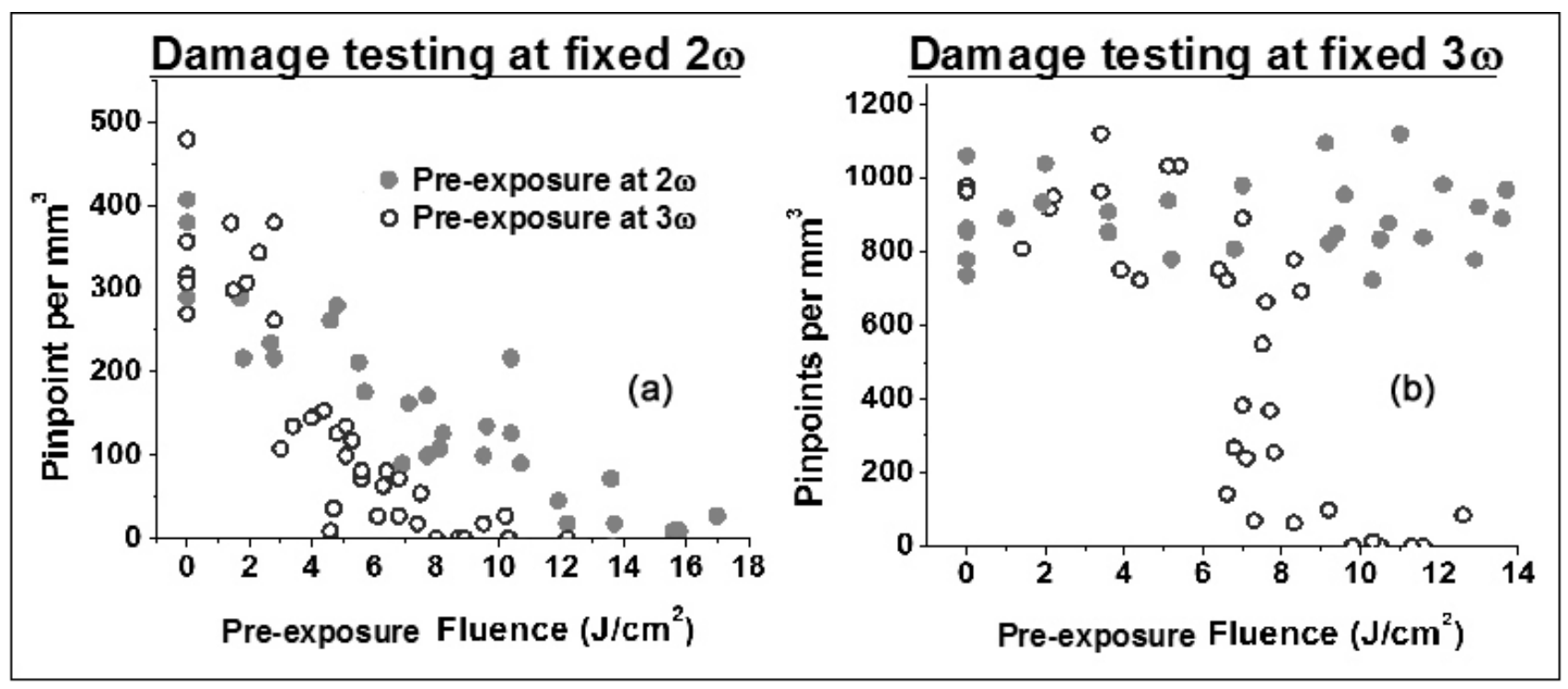

Figure 9. The damage pinpoint density resulting from a) $20 \mathrm{~J} / \mathrm{cm}^{2}$ at $2 \omega$ and b) $16 \mathrm{~J} / \mathrm{cm}^{2}$ at $3 \omega$ versus pre-exposure fluence $(\mathbf{O}=$ preexposed to $3 \omega, \bigcirc=$ pre-exposed to $2 \omega$ ) in DKDP.

\subsubsection{Pre-exposure with different number of pulses}

The behavior of conditioning as a function of the number of conditioning pulses was investigated for damage testing and pre-exposure at both, $2 \omega$ and $3 \omega$. Pristine sites were exposed to a varying number of pulses (between 1 and 1024, multiples of 4) at fixed fluence and then damage tested with a single pulse at fixed fluence. Images were again captured prior to and after damage testing and the total peak pinpoint density resulting from both damage testing and preexposure, as well as the peak pinpoint density resulting from pre-exposure only, was plotted versus the number of preexposure pulses. In each damage testing and pre-exposure frequency configurations the experiment was performed at least twice at different fixed pre-exposure fluences.

Figure 10 shows histograms of the pinpoint density resulting from damage testing at $35 \mathrm{~J} / \mathrm{cm}^{2}$ at $2 \omega$ and pre-exposure at $13 \mathrm{~J} / \mathrm{cm}^{2}$ at $2 \omega$ (shown in Fig. 10a) and damage testing at $17 \mathrm{~J} / \mathrm{cm}^{2}$ at $3 \omega$ and pre-exposure at $10 \mathrm{~J} / \mathrm{cm}^{2}$ at $3 \omega$ (shown in Fig. 10b) as a function of the number of pre-exposure pulses. The dark gray bars indicate the peak pinpoint density resulting from pre-exposure only while the lighter gray bars indicate the total peak pinpoint density resulting from both damage testing and pre-exposure. In both cases, as the number of pre-exposure pulses increases there is a continual steady decrease in the pinpoint density. The data suggests that the first few pulses are the most effective in providing most of the conditioning observed for each fluence. 
(a) Pre-exposure at $13 \mathrm{~J} / \mathrm{cm}^{2}, 2 \omega$

Damage testing at $35 \mathrm{~J} / \mathrm{cm}^{2}, 2 \omega$

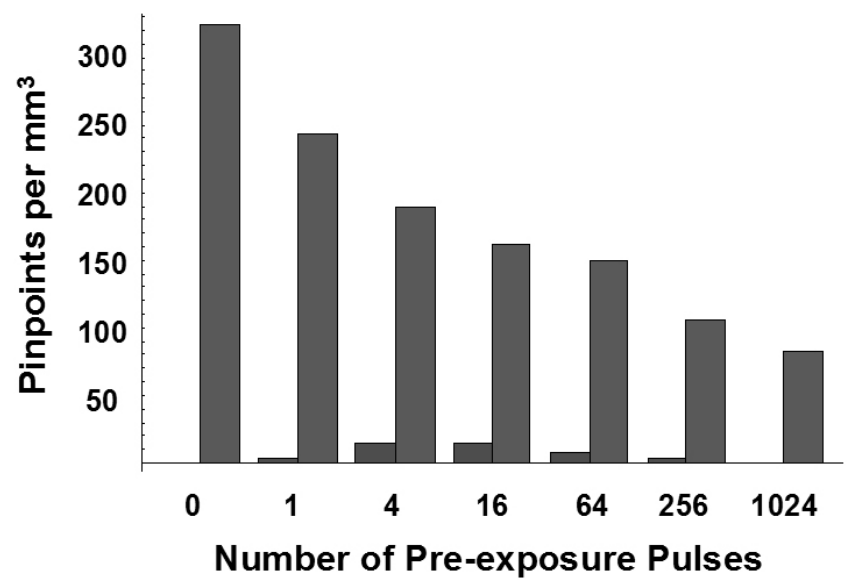

(b) Pre-exposure at $10 \mathrm{~J} / \mathrm{cm}^{2}, 3 \omega$

Damage testing at $17 \mathrm{~J} / \mathrm{cm}^{2}, 3 \omega$

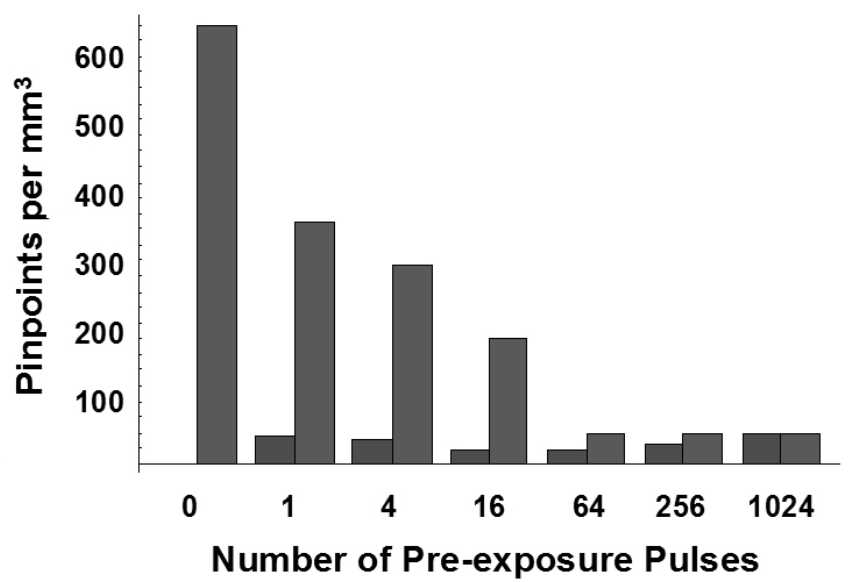

Figure 10: Damage testing at $35 \mathrm{~J} / \mathrm{cm}^{2}$ at $2 \omega$ and pre-exposure at $13 \mathrm{~J} / \mathrm{cm}^{2}$ at $2 \omega$ (a) and damage testing at $17 \mathrm{~J} / \mathrm{cm}^{2}$ at $3 \omega$ and preexposure at $10 \mathrm{~J} / \mathrm{cm}^{2}$ at $3 \omega(\mathrm{b})$ in bulk DKDP as a function of the number of pre-exposure pulses (on log-scale). $\square$ and $\square$ represent the pinpoint density resulting from pre-exposure only and both pre-exposure and damage testing, respectively.

\subsection{Damage Effects Resulting from Simultaneous $2 \omega$ and $3 \omega$ Irradiation}

In order to approximate the conditions taking place during frequency conversion, preliminary experiments on the damage effects resulting from multi-frequency irradiation were also performed. Damage testing under simultaneous exposure to $2 \omega$ and $3 \omega$ was investigated as a function of fluence. Pristine bulk sites were simultaneously irradiated with $2 \omega$ and $3 \omega$ pulses and images of the resulting damage were recorded. In this experiment, the total number of pinpoints arising from the damage testing pulse was counted and the pinpoint density was calculated. In the first case, the $2 \omega$ fluence was held constant at $15 \mathrm{~J} / \mathrm{cm}^{2}$ while the $3 \omega$ fluence was increased in $5-\mathrm{J} / \mathrm{cm}^{2}$ steps from 0 to $20 \mathrm{~J} / \mathrm{cm}^{2}$, while, in the second case, the $3 \omega$ fluence was held constant at $15 \mathrm{~J} / \mathrm{cm}^{2}$ while the $2 \omega$ fluence was increased in $5-\mathrm{J} / \mathrm{cm}^{2}$ steps from 0 to $20 \mathrm{~J} / \mathrm{cm}^{2}$.
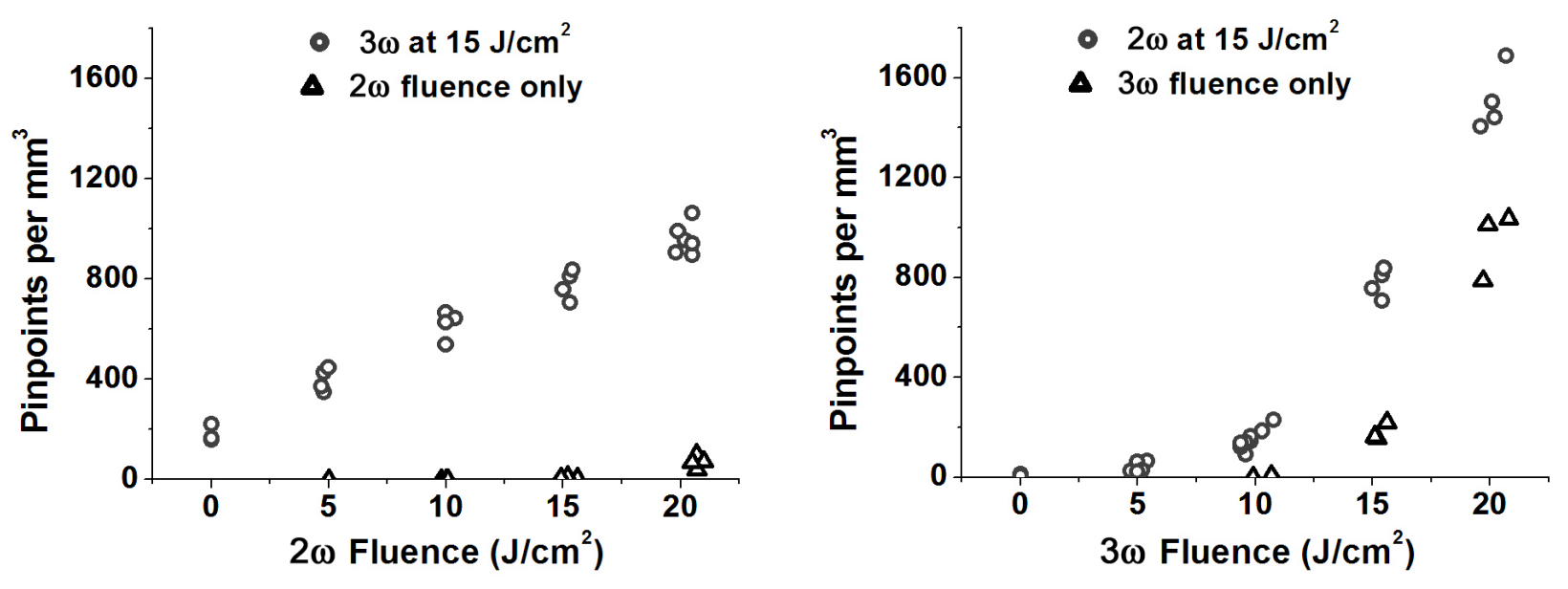

Figure 11. Plots of the pinpoint density versus $2 \omega$ fluence with $3 \omega$ fluence held constant at $15 \mathrm{~J} / \mathrm{cm}^{2}$ (left) and $3 \omega$ fluence with $2 \omega$ fluence held constant at $15 \mathrm{~J} / \mathrm{cm}^{2}$ (right) in DKDP. The damage pinpoint density resulting from only $3 \omega$ and $2 \omega$ exposure is also shown for comparison (open triangles). 
The damage pinpoint densities resulting from the combined $2 \omega$ and $3 \omega$ pulses, for both cases described above, are shown in Fig. 11. The damage pinpoint density resulting from separate $2 \omega$ and $3 \omega$ exposure is also shown for comparison. In both cases, we find that the damage effects at one frequency are enhanced by the presence of the constant fluence at the second frequency. This suggests that the presence of both frequencies during conversion can contribute to enhanced damage effects and hence needs to be considered.

\section{SUMMARY AND FUTURE WORK}

This system exceeds current testing systems performance by incorporating quantitative damage measurements on pinpoint size and density and resulting obscuration as a function of fluence. Current damage testing systems furnish damage probability versus fluence profiles which require complex processing to correlate to operational conditions and extrapolate if a material meets specifications. In addition to measuring the damage threshold fluence, this system measures the amount of damage versus fluence to provide direct information on the expected damage density for operation at a given fluence. The high-resolution damage detection capabilities and data analysis method enable rapid characterization of materials using very little material volume.

We have also demonstrated the ability of the system to rapidly evaluate laser conditioning protocols therefore making feasible future investigations into the effects of varying laser parameters such as frequency, fluence, number of pulses, and pulse-length. The ease in simulating online conditions such as frequency generation is also shown and we find that the damage effects under multi-frequency exposure are considerable.

We are in the process of carrying out experiments that examine the conditioning mechanism in KDP and DKDP crystals by studying their damage behavior as a function of the pre-exposure fluence and the number of pre-exposure pulses, for damage testing and pre-exposure at all combinations of harmonics of the Nd:YAG laser. The damage effects under multi-frequency simultaneous exposure are also being further investigated at variable fluences of the individual frequencies. This will provide detailed information on the expected level of damage arising during harmonic generation in KDP and DKDP frequency doublers and triplers in large-aperture laser systems. The fluence-frequency dependence of the pinpoint density resulting from various multi-frequency fluence combinations will be useful in testing different models for damage initiation. Pump-and-probe experiments will also provide insight into fundamental mechanisms. Finally, we also plan to incorporate into this system a tunable laser to examine laser damage and conditioning for a wide range of photon energies. The dependence of conditioning on both laser pulse-length ${ }^{15}$ and photon energy is essential for the understanding of the fundamental mechanisms of laser damage and conditioning.

It is evident that laser conditioning will improve the performance of materials but it will not eradicate the problem of laser-induced damage. Thus, an effort to identify the damage initiators is required so that a method to remove them from the crystal can be devised. Our experimental approach will help obtain detailed experimental results based on which will physical models can be developed and will lead to a fundamental understanding of the behavior and characteristics of the damage initiators.

\section{ACKNOWLEDGEMENTS}

This work was performed under the auspices of the U.S. Department of Energy by University of California, Lawrence Livermore National Laboratory under contract W7405-Eng.48.

\section{REFERENCES}

1. F. Rainer, F. P. DeMarco, M. C. Staggs, M. R. Kozlowski, L. J. Atherton, and L. M. Sheehan, "A historical perspective on fifteen years of laser damage thresholds at LLNL," in Laser-Induced Damage in Optical Materials: 1993, H. E. Bennett, L. L. Chase, A. H. Guenther, B. E. Newnam, and M. J. Soileau, Eds., Proc. SPIE 2114, 1994. 
2. C. S. Liu, N. Kioussis, S. G. Demos, and H. B. Radousky, "Electron- or Hole-Assisted Reactions of H Defects in Hydrogen-Bonded KDP," Phys. Rev. Lett., 91, 015505, 2003.

3. C. W. Carr, H. B. Radousky, and S. G. Demos, "The Wavelength Dependence of Laser Induced Damage: Determining the Damage Initiation Mechanisms," Phys. Rev. Lett., 91, 127402, 2003.

4. S. G. Demos, M. Staggs, and H. B. Radousky, "Bulk defect formations in $\mathrm{KH}_{2} \mathrm{PO}_{4}$ crystals investigated using fluorescence microscopy," Phys. Rev. B, 67, 224102, 2003.

5. S. G. Demos, M. Yan, M. Staggs, J. J. De Yoreo, H. B. Radousky, "Raman scattering investigation of KH2PO4 subsequent to high fluence laser irradiation," Appl. Phys. Lett., 72, 2367-69, 1998.

6. C. D. Marshall, S. A. Payne, M. A. Henesian, J. A. Speth, and H. T. Powell, "Ultraviolet-induced transient absorption in potassium dihydrogen phosphate and its influence on frequency conversion," JOSA B 11, 774, 1994.

7. M. M. Chirila, N.Y. Garces, L.E. Halliburton, S.G. Demos, T.A. Land, H.B. Radousky, "Production and thermal decay of radiation induced point defects in $\mathrm{KH}_{2} \mathrm{PO}_{4}$ crystals," J. Appl. Phys. 94, 6456, 2003.

8. I. N. Ogorodnikov, V. Y. Yakovlev, B. V. Shul'gin, and M. K. Satybaldieva, "Transient Optical Absorption of Hole Polarons in ADP $\left(\mathrm{NH}_{4} \mathrm{H}_{2} \mathrm{PO}_{4}\right)$ and $\mathrm{KDP}\left(\mathrm{KH}_{2} \mathrm{PO}_{4}\right)$ Crystals", Phys. Solid State 44, 845, 2002.

9. A. K. Burnham, M. Runkel, M. D. Feit, A.M. Rubenchik, R. L. Floyd, T. A. Land, W. J. Siekhaus, and R. A. Hawley-Fedder, "Laser-induced damage in deuterated potassium dihydrogen phosphate," Appl .Opt. 42, 5483-5495, 2003.

10. J. Hue, J. Dijon, and P. Lyan, "The CMO YAG damage test facility," in Laser-Induced Damage in Optical Materials:1995, Harold E. Bennett, Arthur H. Guenther, Mark R. Kozlowski, Brian E. Newnam, M. J. Soileau, Eds, Proc. SPIE 2714, 102-113, 1996.

11. M. J. Runkel and A. K. Burnham, "Differences in bulk damage probability distributions between tripler and z-cuts of KDP and DKDP at $355 \mathrm{~nm}$," in Laser-Induced Damage in Optical Materials: 2000, Gregory J. Exarhos, Arthur H. Guenther, Mark R. Kozlowski, Keith L. Lewis, M. J. Soileau, Eds., Proc. SPIE 4347, 408-419, 2001.

12. J. Hue, F. Y. Genin, S. M Maricle, and M. R. Kozlowski, "Toward predicting the laser damage threshold of largearea optics," in Laser-Induced Damage in Optical Materials: 1996, Harold E. Bennett, Arthur H. Guenther, Mark R. Kozlowski, Brian E. Newnam, M. J. Soileau, Eds., Proc. SPIE 2966, 451-462, 1997.

13. M. J. Runkel, S. M Maricle, R. Torres, J. Auerbach, R. Floyd, R. Hawley-Fedder, and A. K. Burnham, "Effect of thermal annealing and second harmonic generation on bulk damage performance of rapid-growth KDP type I doublers at $1064 \mathrm{~nm}$," in Laser-Induced Damage in Optical Materials: 2000, Gregory J. Exarhos, Arthur H. Guenther, Mark R. Kozlowski, Keith L. Lewis, M. J. Soileau, Eds., Proc. SPIE 4347, 389-399, 2001.

14. M. Loiseau, L. Lamaignere, R. Courchinoux, G. Raze, C. Sudre, M. Josse, T. Donval, and H. Bercegol, "Automatic damage test benches: from samples to large-aperture optical components," in Optical Fabrication, Testing, and Metrology: 2002, Roland Geyl, David Rimmer, Lingli Wang, Eds., Proc. SPIE 5252, 412-422, 2004.

15. J. J. Adams, T. L. Weiland, J. R. Stanley, W. D. Sell, R. L. Luthi, J. L. Vickers, C. W. Carr, M. D. Feit, A. M. Rubenchik, and R. P. Hackel, "Pulse-length dependence of laser conditioning and bulk damage in $\mathrm{KD}_{2} \mathrm{PO}_{4}$," this SPIE proceedings. 